\title{
Suggestion for an Innovative Way of Attracting EFL College- Level Students in Korea Using Transmedia Storytelling
}

\author{
Ryu, Do Hyung \\ (Kookmin University)
}

\begin{abstract}
Ryu, Do Hyung. (2018). Suggestion for an innovative way of attracting EFL college-level students in Korea using transmedia storytelling. STEM Journal, 19(2), 47-64.
\end{abstract}

\begin{abstract}
The purpose of the paper is to suggest an innovative way of attracting EFL collegelevel students, especially low-intermediate ones, in Korea. It is shocking that most low-intermediate students tend to give up English language learning in school. To help them restore their confidence, this study examined how to use the concept 'transmedia storytelling' (Jenkins, 2006, 2010). For this, three forms of media were used to teach the story Robinson Crusoe: a printed text, a movie and an animation. Each type of media had a different storyline. Fifteen students participated in the experiment, all with a TOEIC score of less than 500. For the first month, the participants read the written text and for the second month, they watched and discussed the movie and the animation. For the final month, they read the main text again. Multi-word units (MWU) are tested, especially fusion, with the main text before and after watching the movie and the animation. The second test (Q \& A) was administered with the movie and the animation. Finally, the participants handed in comments about the use of transmedia storytelling. Results from the study indicate that about half became information seekers, not language learners.
\end{abstract}

\section{INTRODUCTION}

As is well known, the English language is the world lingua franca, so it is no wonder that English language learners study hard in the classroom. Strangely enough, many Korean university and college students tend to avoid English language learning in the classroom. Why does this happen in Korea? Before looking for some answers, it would be desirable to know who these 'many Korean university and college students' are. Specifically there are students who have TOEIC scores of around 500, indicating low intermediate language proficiency. This category comprises more than half of the 
population of university and college students, though some universities are different. Some say that they are poorly motivated in learning English. When some of them have been interviewed and asked the question, "Do you want to learn English?" often they gave unexpected answers. They said they want to learn English. They want to speak English fluently. Simply, they do not know how to achieve fluent proficiency in English. They say that EFL classroom learning is boring. They say that they simply know classroom learning is not trustworthy.

For trying to solve this problem, the study suggests an innovative way for students to feel English language learning is worth trying. As an EFL teacher, what to do first is to expose them to an English environment. It is considered to be natural that foreign language learning starts from exposure, to input, then intake to output (Becker, 2007; Ellis, 2002; Gass \& Selinker, 1994; Wang, 2010). It could be said that students don't need to be taught everything necessarily to use English productively. There is the proverb that we may take a horse to the water but cannot make it drink. What teachers can do is to try to make students feel interested in learning English. What they learn about English is all their share. If teachers 'teach' them what to study about the English language, most of them will probably be repulsed. This phenomenon is what the teachers have learned from long teaching experience.

In this paper, the concept 'transmedia storytelling' will be used as a teaching approach. It is defined as "a process where integral elements of a fiction get dispersed systematically across multiple delivery channels for the purpose of creating a unified and coordinated entertainment experience" (Jenkins, 2010, p. 944). For this, three different media types of the story, Robinson Crusoe, will be suggested: a print text, a movie, and an animation. First, the printed text will be taught to students. It is expected that they will be reluctant to learn English. Then a movie will be offered to them and they will discuss similarities and differences between the two media. Then an animation will be offered to them and they will do the same work together. Finally they will come back to the printed text and will be observed for their change, comparing before and after using the other two media.

\section{LITERATURE REVIEW}

Transmedia refers to changing media, for example 'from books to films to video games'. This is the newly developing field of research and there has not been much research on this subject yet. Through media changes, storytelling is effectively transferred to people. For example, if students read Robinson Crusoe (Hopkins \& Potter, 2000) and then watch the movie, Robinson Crusoe (Hardy \& Miller, 1997) and then watch the animation, Robinson Crusoe (Kesteloot \& Stassen, 2016), the same character may be projected 
differently into their minds. Naturally they might actively participate in creating and telling their own stories about the main character. Jenkins (2003) says that in transmedia storytelling, "moving characters from books to films to video games can make them stronger and more compelling" (p. 1).

Later, Jenkins (2006) writes this about transmedia storytelling:

A transmedia story unfolds across multiple media platforms, with each new text making a distinctive and valuable contribution to the whole. In the ideal form of transmedia storytelling, each medium does what it does best - so that a story might be introduced in a film, expanded through television, novels, and comics; it would might be explored through game play or experienced as an amusement park attraction. Each franchise entry needs to be self-contained so you don't need to have seen the film to enjoy the game, and vice versa. Any given product is a point of entry into the franchise as a whole. Reading across the media sustains a depth of experience that motivates more consumption. Redundancy burns up fan interest and causes franchises to fail. Offering new levels of insight and experience refreshes the franchise and sustains consumer loyalty. (pp. 95-96)

In this passage, Jenkins (2006) says that redundancy ruins fans' interest. It is like the feeling EFL learners have about clichéd materials. As mentioned before, Korean EFL students seem to be sick of studying reading materials which have dull and predictable contents. Jenkins (2006) continues to say that using transmedia offers 'new levels of insight and experience' and consequently it holds fans' interest. Even though Jenkins' idea is right, nobody knows what will happen to our EFL Korean students. They might get to love learning English even in the traditional classroom. Pratten (2015) also points out a traditional definition of transmedia storytelling would be telling a story across multiple platforms, preferably allowing audience participation, such that each successive platform heightens the audience' enjoyment. To do this successfully, the embodiment of the story in each media needs to be satisfying in its own right while enjoyment from all the media should be greater than the sum of the parts.

The problem with the traditional definition is that it is focuses on the how of transmedia storytelling and not the why - it describes the production and not the consumption. If instead the teachers place the audience at the center of the definition then teachers get much better focus for their works. Now transmedia storytelling could be described as: taking the audience on an emotional journey that goes from moment-to-moment.

A "moment" is a point in time when we are totally absorbed in the present. 
Most of our lives are spent in an endless stream of events that mean little or nothing to us; time is like running water - we don't notice the millions of tiny droplets that make up the stream. We want to take one or more of these millions of tiny droplets of time and make them mean something more - we want to make them memorable and meaningful... to make them a moment. (p. 2)

Pratten (2015) does not mention references for his 'traditional definition' but his definition is much clearer than Jenkins' one. Then does Jenkins' definition belong to tradition or a new era? At one time Jenkins and Frank Rose talked about transmedia and deep media, ${ }^{1}$ which is similar to transmedia conceptually. Jenkins asks Rose about 'the core characteristics of deep media' (Rose, 2009a, 2009b) and the relationship between the two media. Jenkins (2011) wrote Rose's answer as follows; "to me it's mainly a question of emphasis. Are we focusing on the process or the goal? Transmedia, or cross media, puts the emphasis on a new process of storytelling: How do you tell a story across a variety of different media? Deep media puts the focus on the goal: to enable members of the audience (for want of a better term) to delve into a story at any level of depth they like, to immerse themselves in it".

Looking at his explanation about the two media, Rose (2009a) considers that Jenkins' term (2011), transmedia, focuses on 'how.' Instead deep media prefers to 'enable members of the audience to delve into a story', which refers to a new approach. In this paper, this research focuses on transmedia rather than deep media because movies and a text are going to be used for the experimentation. Basically movies and texts are non-interactive (Pratten, 2015). In this sense, audience involvement may not be easy with non-interactive media like movies and books. In order to facilitate audience involvement, the storyline should be strengthened. In other words, Jenkins' transmedia should focus on production for less interactive media ${ }^{2}$. On the other hand, interactive oriented media such as games do not like to strengthen storylines. Bartle (2004) who is an expert on the virtual world says the following about storylines.

Virtual world designers can't add story, they only can add content. Content provides experiences that can be made by those who come through or observe them into story. If the content itself is story, players' own stories become worthless incidentals. (p. 663)

\footnotetext{
${ }^{1}$ Deep media is a term by Rose (2011).

2 Jenkins (2010) describes his personal experience of teaching a course with transmedia storytelling.
} 
Another term besides transmedia and deep media is cross media by Dena $(2004,2008)$. Davidson (2010) gives a better description of cross media; "While cross-media is not necessarily a particularly new concept-advertising, for example, has long tried to incorporate unified messages across multiple media from billboards to magazines to television - the rapid growth of digital technology and the degree of interconnectivity it has enabled has dramatically changed the reach and nature of cross-media communications (p. 4)". Also Davidson (2010) explains it by good examples: A good example of cross-media communications at work today is the transmedia Star Wars franchise. "We can take part in the Star Wars experience by viewing the movies (in the theatre or on DVDs packed with extra features), by playing Star Wars video games (across all game platforms), by reading Star Wars comics and novels, by participating on Star Wars interactive websites, by listening to Star Wars soundtrack CDs, by purchasing Star Wars merchandise, and on and on. The key point here is that the overarching stories in the Star Wars universe are integrated and threaded together across all of these media in what the franchise calls the Expanded Universe. Star Wars is a well-conceived and implemented cross-media communication experience" (p. 4).

The above passage describes how cross media emphasizes production like Jenkins' transmedia. All the information from the Star Wars universe is put together to make their storylines stronger. In this sense, cross media is very close to transmedia (Davidson, 2010). Due to space limits, the subtle differences between the two terms will not be dealt with. Instead the above Star Wars example by Davidson will give an idea what cross media is and how close it is to transmedia.

\section{DESIGN}

\section{Participants}

Fifteen freshmen from one university participated in this experiment. Their average TOEIC scores are less than 500. They had lessons for twelve weeks, two times a week, for one and a half hours each time.

\section{Transmedia Materials}

The first media used in the classroom was the graded reader, the Penguin Reader, Robinson Crusoe (Hopkins \& Potter, 2000). It is an elementary level text with 600 
headwords ${ }^{3}$. Even though it is easy to read and is a heavily abridged version, it keeps the basic structure and meaning of the original version. The reason this easy book was used with the students was to reduce their study burden. From long teaching experience, it has been learned that students with TOEIC scores of less than 500 basically hated EFL books as they are hard to read. Another reason to use this book is that they can learn basic multiword units.

Multi-word units have been positively recognized since the end of $20^{\text {th }}$ century (Boers \& Lindstromberg, 2005; Irujo, 1993; Lewis, 1993; Nattinger \& DeCarrico, 1992; Schmitt, 2004; Willis, 1990; Wray, 2000, 2002). A lot of research into multi-word units has been conducted in Korea (Lee, 2016; Rho, 2018; Seo, 2017). Among them, Wray (2002) cites Peters (1983) term, fusion ${ }^{4}$ which is considered to be a sequence of words. Other multiword units are acquired without grammar, but fusion starts with grammatical analysis. For example, 'I love you' is a sentence in the pattern of SVO. When it is frequently used, people can use the sentence like a multi-word unit without the help of grammar. Such fusions are ubiquitous in graded books like the version of Robinson Crusoe used.

The second type of media is the movie, Robinson Crusoe. Its running time is 105 minutes. This movie shows how Daniel Defoe wrote Robinson Crusoe. The story of the movie is totally different from that of the Penguin Reader book. The main protagonist, Crusoe, is a Scottish gentleman who has some experience in the Royal Navy and the British army. Later this experience helps him fight cannibals on the island. Another difference is that he leaves England because he accidentally kills his friend Patrick due to his love for Mary and Patrick's brothers threaten Robinson. He promises Mary that he would come back one year later to marry her. But he comes back six years later. There are so many differences compared to the book in addition to these.

The third type of media is the animation, Robinson Crusoe. Its running time is 90 minutes. It is true that this animation is based on the story of Robinson Crusoe by Daniel Defoe but it is quite different from the Penguin book and the movie. The story is narrated from the point of view of the island's animals.

To help understanding, the plot of the animation is outlined.

Mardi, a young parrot, lives on an idyllic island full of other animals, dreaming of a day when he can finally leave to discover the rest of the world. After a horrendous storm, Mardi and his friends discover a strange creature washed up on the shore: Robinson Crusoe. It's up to Mardi and the other animals on the island to tame this new arrival. Mardi sees this as a chance for

\footnotetext{
3 To review the effect of simplified version, read Crossley, Louwerse, McCarthy, \& McNamara (2007).

${ }^{4}$ Read Peters (1983, pp. 80-85) for review of the term, fusion.
} 
adventure, and maybe even to leave his island! ("Robinson Crusoe,” n.d.)

This animation is very humorous, compared with the other forms of Robinson Crusoe.

In this experiment, these three media are all used. However, the main media is the graded reader text. The purpose of this paper is to attract low-level students to reading texts and naturally the text media is focused on this.

\section{Procedure}

As mentioned above, the purpose of the study is to observe whether participants would change their attitudes from no interest to interest in English language learning with the help of other media. The procedure followed is as follows.

First, participants read the graded reader with their teacher. There were lectures from the teacher and presentations from participants. To encourage their study, the teacher sometimes used pop songs. What they are supposed to learn is chunks (e.g., idiomatic expressions, conventional forms, grammatically simple and easy sentences called fusion, etc.). Specifically speaking, participants tried to work for a connection between form and meaning. It was expected that this would take around one month. The teacher is supposed to check how they respond to the teacher's teaching method.

Second, the participants watch the movie. There will be a lot of discussions about differences of the story between the Penguin Reader and the movie. It will take about two weeks.

Third, the participants watch the animation with discussions about the different plots and stories among the three media. It will take about another two weeks. Fourth, the participants come back to the graded reader text again. They will do the same work in this stage, that is, collecting chunks (mainly, fusion).

\section{Evaluation}

In the first stage with the graded reader, it is the first concern to check how well the participants make the connection between form and meaning. For this, the teacher provides L1 translation for passages of the graded reader book. Here L1 translation is very important (Cook, 2001; Liao, 2006). Most L2 learners do not have intuitions of L2 language, so they find it hard to pick L2 chunks directly from the English text. Instead when they are provided with L1 translation, it's easy to pick L1 chunks directly thanks to L1 intuition. In the classroom, the participants are supposed to make presentations about this. If they collect as many chunks as possible, they get good scores.

In the second and third stages, they have discussions about the movie and animation. 
After the discussions, they hand in reports to their teacher. Then the teacher will analyze the reports under some criterion: 1) the attitude about the lessons, 2) the interest in the story, and 3) changes within the participants themselves. These will be quantitatively counted.

The fourth stage is basically the same as the first one. Also scores of the fourth stage will be compared with those of the first. The score difference will prove if there has been an improvement or not.

\section{RESULTS AND ANALYSIS}

\section{The First Stage and the Fourth Stage}

Question 1 and 5 and the results are as follows:

Question 1. Read the passage from your text book, Robinson Crusoe. Please underline as many word sequences (or chunks) as possible if you think they are worth remembering.

Question 5. Do the same job as in Question 1.

TABLE 1

Results of the First \& the Fourth Stages

\begin{tabular}{ccccccc}
\hline \hline & \multicolumn{3}{c}{ First stage (Q1) } & \multicolumn{3}{c}{ Fourth stage (Q5) } \\
Participants & MWU(3) & Fusion(8) & Total(11) & MWU(6) & Fusion(13) & Total(19) \\
\hline 1 & $3(100 \%)$ & $3(38 \%)$ & $6(55 \%)$ & $2(33 \%)$ & $8(62 \%)$ & $10(53 \%)$ \\
2 & $1(33 \%)$ & $5(63 \%)$ & $6(55 \%)$ & $2(33 \%)$ & $5(38 \%)$ & $7(37 \%)$ \\
3 & $1(33 \%)$ & $5(63 \%)$ & $6(55 \%)$ & $3(50 \%)$ & $9(69 \%)$ & $12(63 \%)$ \\
4 & $2(67 \%)$ & $1(13 \%)$ & $3(27 \%)$ & $2(33 \%)$ & $4(31 \%)$ & $6(32 \%)$ \\
5 & $1(33 \%)$ & $8(100 \%)$ & $9(82 \%)$ & $2(33 \%)$ & $7(54 \%)$ & $9(47 \%)$ \\
6 & $1(33 \%)$ & $1(13 \%)$ & $2(18 \%)$ & $0(0 \%)$ & $5(38 \%)$ & $5(26 \%)$ \\
7 & $1(33 \%)$ & $4(50 \%)$ & $5(45 \%)$ & $2(33 \%)$ & $4(31 \%)$ & $6(32 \%)$ \\
8 & $1(33 \%)$ & $3(38 \%)$ & $4(36 \%)$ & $1(17 \%)$ & $5(38 \%)$ & $6(32 \%)$ \\
9 & $1(33 \%)$ & $4(50 \%)$ & $5(45 \%)$ & $4(67 \%)$ & $4(31 \%)$ & $8(42 \%)$ \\
10 & $3(100 \%)$ & $7(88 \%)$ & $10(91 \%)$ & $4(67 \%)$ & $11(85 \%)$ & $15(79 \%)$ \\
11 & $3(100 \%)$ & $5(63 \%)$ & $8(73 \%)$ & $4(67 \%)$ & $7(54 \%)$ & $11(58 \%)$ \\
12 & $1(33 \%)$ & $4(50 \%)$ & $5(45 \%)$ & $1(17 \%)$ & $8(62 \%)$ & $9(47 \%)$ \\
13 & $0(0 \%)$ & $4(50 \%)$ & $4(36 \%)$ & $2(33 \%)$ & $3(23 \%)$ & $5(26 \%)$ \\
14 & $1(33 \%)$ & $2(25 \%)$ & $3(27 \%)$ & $1(17 \%)$ & $3(23 \%)$ & $4(21 \%)$ \\
15 & $1(33 \%)$ & $1(13 \%)$ & $2(18 \%)$ & $1(17 \%)$ & $1(8 \%)$ & $2(11 \%)$ \\
\hline
\end{tabular}

\footnotetext{
${ }^{5}$ Refer to Appendix for test passages.
} 
For convenience, the results of the first stage and the fourth stage were put in the same table in order to observe how the participants developed from the first stage to the fourth stage. Comparing figures of the first stage with those of the fourth stage, a development can be shown, except for participants 5 and 15. In this respect, the use of transmedia appears to be effective.

However, when you look at the proportion of the first stage to the fourth stage, the result is reversed. Apart from four participants (3, 4, 6, and 12) the other eleven participants received low scores from the ratio perspective.

What can be said about this phenomenon? In the results of MWU, it can be seen that they are fixed phrases which means participants should memorize them, if they want to know them. This is why most of the participants got less than $50 \%$ both in the first and the second stages. On the other hand, fusion is a language form which is not fixed. For example, at the expression 'I love you' has many substitutions such as 'She loves me', 'He loves her', 'I love her', etc. This means that fusion is very flexible in its ability to choose. Also it is easy to pick.

But there is another problem about fusion. In the first stage, nine participants got $50 \%$ or more. In the second stage, six participants got more than $50 \%$. Comparing the ratios of these two stages, it is hard to find any development. What can be said about this phenomenon? As mentioned above, fusion is easy form for making different choices. If you already know some forms, you don't have to choose. The fourth stage (13) has more fusions than the first stage (8). So if you know more forms already in the second stage than in the first stage, you can automatically choose less in the second stage than in the first stage.

\section{The Second and Third Stages}

Question 2 and 3, and the results are as follows:

Question 2. Read the first three passages. In the first and second passages, the savage was called 'Friday' and the parrot was called 'Tuesday' in the third passage. Please describe how the names were given to the savage and the parrot respectively.

Question 3. Read the second three passages and describe the relationships between 'Friday' and his hometown and between 'Tuesday' and her outside world.

TABLE 2

Results of the Second Stage and the Third Stage

\begin{tabular}{cc}
\hline Participants & Q2 \& Q3 \\
\hline All of them & Correct \\
\hline
\end{tabular}


This time $<$ Table $2>$ looks very simple. All the participants answered Question 2 and Question 3 correctly. This means that the participants enjoyed the movie and the animation with their visuals and strong storylines.

Regarding Question 2, all the participants answered correctly. Correct answers were clearly expressed in the test passage. On the other hand, Question 3 was not easy to answer. They had to figure out evidence for the right answers in the test passage in which the storyline was a little complicated.

This test gives important implications to the classroom. In the introduction, it was mentioned that many current EFL college-level students were reluctant to learn the English language, even though they wanted to be fluent speakers. Before administering the tests to them, it was not clear whether the participants would do the tests sincerely. As can be seen, the result in the $<$ Table $2>$ showed they took the tests seriously and they became increasingly interested in contents and the story.

However, there is a need to find out why this has happened to the participants because the result is unusual. Question 4 might give us some clues to find out the reasons. They were looking for what they really wanted to know. What gave them this extraordinary power? It can be said that the answer is the strong storyline and the use of various media.

Question 4 and the results are as follows:

Question 4. You've met different 'Robinson Crusoes' through cross media. Write down your impressions of the Robinson Crusoe in the textbook and the Robinson Crusoes in the movie and animation. Also write down your attitude about the textbook when you read the textbook before and after viewing the other two media.

TABLE 3

Results of Comments ${ }^{6}$

\begin{tabular}{|c|c|}
\hline Participants & Comments about Q4 \\
\hline 1 & No answer \\
\hline 2 & Feel it is easy to read the main text again \\
\hline 3 & Agree with using as many media as possible \\
\hline 4 & $\begin{array}{l}\text { Can pay attention to the main text because the other media provided } \\
\text { background for better understanding }\end{array}$ \\
\hline 5 & Each medium has a different story. I can create my own story. \\
\hline 6 & Enjoy the main text thanks to the other media \\
\hline 7 & Different media approaches to the same story are important and enjoyable \\
\hline 8 & The other media offered me a new insight to see Robinson Crusoe \\
\hline 9 & Bored because the other media are much more interesting \\
\hline 10 & The other media help me to add missing information into the main \\
\hline 11 & Comparison among the three media is fun. \\
\hline
\end{tabular}

${ }^{6}$ Comments were summarized for the convenience of reading. 
Suggestion for an Innovative Way of Attracting EFL College-Level Students

in Korea Using Transmedia Storytelling

12 Better understand the text thanks to movie scenes and the parrot.

13 Enjoy the main text thanks to the other media.

14 Not enjoy the main text due to the lack of visuals

15 Enjoy the main text thanks to the other different media.

Read $<$ Table $3>$ Participant 1 did not answer. Participant 9 and 14 answered negatively. The other twelve participants made positive comments to us indicating their good impressions about the use of transmedia. Participants 6, 7, 11, 13, and 15 mentioned enjoyment when they would read the main text again. Participants 2, 4, 10, and 12 referred to better understanding. Participants 5 and 8 mentioned active participation in reading the main text.

For convenience, the three things mentioned above are described again.

- Participants 6, 7, 11, 13, \& $15 \rightarrow$ enjoyment

- Participants 2, 4, 10, \& $12 \rightarrow$ better understanding

- Participants $5 \& 8 \rightarrow$ active participation

The first 'enjoyment' means more than learning. One third of all the participants mentioned that they can enjoy English reading. Considering their TOEIC scores are less than 500, it can be seen that they have made a huge leap. Of course, it should not be overlooked that their comments are based on the use of transmedia. The second 'better understanding' means learning itself. One quarter of all the participants did not show an attitude change. The third 'active participation' shows their willingness to express themselves, even though only two participants belong here.

In sum, the participants changed their attitude toward the English language learning through the use of transmedia. Considering that their proficiency level was lower than intermediate, it cannot be denied that the use of transmedia can change their learning style in the EFL classroom.

\section{CONCLUSION}

Pratten (2015) says that "a policy of 'one size fits all' is no longer expected or acceptable" (p. 4). This research showed the English teaching method to use three sizes or types of media as study material. Each media form had its own storyline, but this did not bother the participants. They loved the different stories. It seems that such differences stimulated the participants to pay attention to each story and to create their own stories.

Then what about their language learning? When they were instructed through transmedia, could it be said that their language learning was effective? It cannot be 
asserted that to use transmedia can guarantee their language improvement. But it can be confidently said that they have changed their attitude about the main written text. When they entered the classroom at first, carrying the main textbook, they did not expect anything special. They were fully accustomed to reading written pages in junior and senior high schools. They could predict what might happen in the classroom: reading, translating, grammar explanation, and comprehension checks, etc. All that they could imagine was simply the-same-thing-happening-again, which means simply being bored. Considering this, it can be said that their change of attitude is a great leap for them. The results show that they are not simply language learners and they are information seekers. Of course, language knowledge is part of the information which our participants are trying to seek. One of the main focuses of this research is that they approach language not as language learners but as information seekers. So they can actively participate in finding information which they want to know more about.

As is well known, it is common to use only one type of media as a textbook in the classroom. It is not that using one type of media is wrong. It should be emphasized that teachers should know who EFL students are.

English is an international language and should be taught in the EFL classroom. This is not arguable at all. Some people can say that EFL teachers let low-intermediate learners go. This could be quite understandable from a practical perspective. However, from an educational perspective, teachers should have to do their best to help their students fit into society. Teachers should have to lead them to grasp more opportunities for a better life.

A practical conclusion drawn by the study is that the use of transmedia can be a good tool to draw low-intermediate learners back into English language learning. The results of this study showed that unlike in the past, they can enjoy the English world. This should not be overlooked and much more research is needed in this area to understand and motivate the students in a digital age.

\section{REFERENCES}

Bartle, R. A. (2004). Designing virtual worlds. Indianapolis, IN: New Riders.

Becker, B. (2007). Exposure is not enough: The interaction of exposure and efficiency in the second language acquisition process. The International Journal of Language Society and Culture, 23, 1-9.

Boers, F., \& Lindstromberg, S. (2005). Finding ways to make phrase-learning feasible: The mnemonic effect of alliteration. System, 33(2), 225-238.

Cook, V. (2001). Using the first language in the classroom. The Canadian Modern Language Review, 57(3), 402-423. 
Crossley, S. A., Louwerse, M. M., McCarthy, P. M., \& McNamara, D. S. (2007). A linguistic analysis of simplified and authentic texts. The Modern Language Journal, 91(7), 15-30.

Davidson, D. (2010). Cross-media communications: An introduction to the art of creating integrated media experiences. Pittsburgh, PA: ETC Press.

Dena, C. (2004, November 15th). Current state of cross media storytelling: Preliminary observations for future design. Delivered by Monique de Hass at Crossmedia communication in the dynamic knowledge society networking session. European Information Systems Technologies Event. The Hague, Netherlands.

Dena, C. (2008). Should we? Could we? Would we? Films in the age of cross-media production. Retrieved from https://www.slideshare.net/christydena/should-wecould-we-would-we-films-in-the-age-of-crossmedia-production-presentation?typ e=powerpoint

Ellis, N. C. (2002). Frequency effects in language processing. Studies in Second Language Acquisition, 24, 143-188.

Gass, S. M., \& Selinker, L. (1994). Second language acquisition: An introductory course. Broadway, NY: Lawrence Erlbaum Associates.

Hardy, R., \& Miller, G. (Directors). (1997). Robinson Crusoe [Motion picture]. United States: Miramax.

Hopkins, A., \& Potter, J. (Eds.). (2000). Penguin readers: Robinson Crusoe (Retold by Nancy Taylor). Harlow, UK: Pearson Education.

Irujo, S. (1993). Steering clear: Avoidance in the production of idioms. International Review of Applied Linguistics in Language Teaching, 31(3), 205-219.

Jenkins, H. (2003, January 15). Transmedia storytelling. Moving characters from books to films to video games can make them stronger and more compelling. Technology Review. Retrieved from http://www.technology review.com/biote ch/13052/

Jenkins, H. (2006). Convergence culture: Where old and new media collide. New York \& London: New York University Press.

Jenkins, H. (2010). Transmedia storytelling and entertainment: An annotated syllabus. Continuum, 24(6), 943-958. doi: 10.1080/10304312.2010.510599

Jenkins, H. (2011, January 26). "Deep media," transmedia, what's the difference?: An interview with Frank Rose (part one) [Blog post]. Retrieved from http://henryjenkins.org/blog/2011/01/deep_media_transmedia_whats_th.html

Kesteloot, V., \& Stassen, B. (Directors). (2016). Robinson Crusoe [Motion picture]. United States: Illuminata Pictures.

Lee, J.-H. (2016). Memorizing word combinations through double translation: With reference to Forrest Gump. STEM Journal, 17(1), 97-115.

Lewis, M. (1993). The lexical approach: The state of ELT and the way forward. London: 
Language Teaching.

Liao, P. (2006). EFL learners' beliefs about and strategy use of translation in English learning. RELC, 37(2), 191-215.

Nattinger, J., \& DeCarrico, J. (1992). Lexical phrases and language teaching. Oxford: Oxford University Press.

Peters, A. M. (1983). The units of language acquisition. Cambridge, UK: Cambridge University Press.

Pratten, R. (2015). Getting started with transmedia storytelling: A practical guide for beginners $\left(2^{\text {nd }}\right.$ ed.). London: Create Space Independent Publishing Platform. Retrieved from https://talkingobjects.files.wordpress.com/2011/08/book-2-robertpratten.pdf

Robinson Crusoe. (n.d.). Retrieved from http://www.engelsizfestival.com/en/?page $\mathrm{id}=7635$

Rho, Y.-A. (2018). A study on the characteristics of vocabulary types in the movie The Holiday. STEM Journal, 19(1), 43-64.

Rose, F. (2009a, November 19). How trans is your media? (Part 1) [Blog post]. Retrieved from http://www.deepmediaonline.com/deepmedia/2009/11/how-trans-is-yourmedia-part-1.html

Rose, F. (2009b, November 24). How trans is your media? (Part 2) [Blog post]. Retrieved from http://www.deepmediaonline.com/deepmedia/2009/11/how-trans-is-yourmedia-part-2.html

Rose, F. (2011). The art of immersion: How the digital generation is remaking Hollywood, Madison avenue, and the way we tell stories. New York, NY: W.W. Norton.

Schmitt, N. (2004). Formulaic sequences: Acquisition, processing, and use. Amsterdam/Philadelphia: John Benjamins.

Seo, J.-Y. (2017). The role and scope of word combinations in the American TV series Shameless: On the basis of word combinations and free word combinations. STEM Journal, 18(1), 27-45.

Wang, X. (2010). Features of input of second language acquisition. Journal of Language Teaching and Research, 1(3), 282-284. doi:10.4304/j1tr.1.3.282-284.

Willis, D. (1990). The lexical syllabus. London: Harper Collins.

Wray, A. (2000). Formulaic sequences in second language teaching: Principle and practice. Applied Linguistics, 21(4), 463-489.

Wray, A. (2002). Formulaic language and the lexicon. Cambridge, UK: Cambridge University Press. 
APPENDIX

The underlined parts are what we expect our students to learn as fusion. There are eleven in total, eight fusions and three are multi-word units (e.g., 'in the year 1632' and 'in the north of England').

Media 1 (the textbook)

I was born in the year 1632, in York, a city in the north of England. I came from a good family, but I always wanted to go to sea. My father was from Germany. He came to York when he was a young man. My first name is Robinson, because that is my mother's family name. My father's last name was Kreutznaer, but English people say this. Now I am Robinson Crusoe.

The next three passages were given to the participants.

Media 1(the textbook)

We walked to the big cave near my country house. My slave was very tired and hungry. I gave him bread, dry fruit and water. Then I made a bed for him and he slept for a short time.

When he woke up, my slave came out of the cave to me. Again he fell on the ground and put my foot on his head. I understood him and smiled at him. Then I began to speak to him. I said the names of many things in English. He said the words after me. Then I said, 'Your new name is "Friday”, because today is Friday. We will remember this day with your name.' I also taught him my name: 'Master'. Then we drank some milk and ate corn cakes. Friday smiled and enjoyed this food and drink. (Hopkins, \& Potter, 2000, p. 21)

Media 2 (movie)

Crusoe:(narration) That he was a savage was indisputable... and yet he seemed to be a decent fellow at heart. In time, I might even turn him from his pagan ways. Perhaps this was my mission. Crusoe: (to the savage) What's your name?

Savage: (no response)

Crusoe: What about Hamish? 1 had a brother called Hamish.

Crusoe: (to hear Rooster crows and to himself) What day is it? Thursday? No, it's not. It's Friday.

Crusoe: (to himself) Friday. (to the savage) Friday.

Savage: (to repeat with doubt) Friday.

Crusoe: (to the savage) Friday. (points to himself to the savage) Master.

Savage: Master?

Crusoe: (points himself) Master. (to the savage) Friday.

Savage: (repeat and learn) Master. Friday.

Crusoe: (laughs) Aye. 
Crusoe: (to himself) Friday. (the movie, 1997, 00:37:36 - 00:38:52)

Media 3 (animation)

Crusoe: (to his dog) Did you hear that? Over there. Oh, look, it's a bird, a beautiful parrot. So, Aynsley, that's what all the fuss was about. Those ratters were after the bird. You've done good, old boy.

Crusoe: (to the parrot) And you... We're going to fix you up straight away.

(animation, 2016, 00:34:41 - 00:36:41)

Crusoe: (searching the parrot's wound) This should only take a minute. It's just dislocated.

But it's going to hurt a bit... (fixing her wing) Don't worry, you'll feel better in a day or two,

though you won't be able to fly right away.

Crusoe: (to the parrot) Well, then, I suppose you'll need a name if you're going to stay here for a while. Let's see. By my reckoning, today's Tuesday. That's as good a name as any, eh?

Can you say Tuesday? Tuesday? Well, not quite. But that's a start. Take care of our new friend, boy. (animation, 2016, 00:36:34 - 00:37:13)

The following passages were also given to the participants.

\begin{tabular}{l}
\hline Media 1 (the textbook) \\
Years later, Friday and I were busy one morning in the garden. \\
'O asked him, 'Friday, do you want to see your country one day?' \\
'What will you do there?' \\
'I will tell my people about corn bread and dry fruit, about goat meat and books. I will tell them \\
about you, Master. You are kind and good. You helped me. \\
'Friday, we can make a boat. You can go to your home,' I told him. \\
'Why are you angry with me?' asked Friday. \\
'I am not angry with you,' I answered. \\
'Why are you sending me away?' \\
'Don't you want to be at home?' I asked. \\
'Yes, but with Master,' Friday answered. \\
'But why?' \\
'Friday loves Master. Master can teach my people many things. You will come with me in the \\
boat.' (Hopkins, \& Potter, 2000, p. 25)
\end{tabular}

Media 2 (movie)

Crusoe:(narration) I had not forgotten who it was... that had brought Friday to my island... nor the Iikelihood of their return. The Nemurs, it seemed, were the dominant tribe... on Friday's island... and Friday had been offered by his own peopIe... as a tribute to these savages. (Hardy \& 
Miller, 1997, 00:48:57 - 00:49:10)

Crusoe: The Nemurs will come back.

Friday: With new moon... many, many warriors will come. Want your magic.

Crusoe: Mmm. Well, we can't fight them all. We could build a boat. Go away. Go to your island. Friday: No. We cannot go to my island.

Crusoe: Why not?

Friday: Cannot go. Can never go. 1 am a dead man.

(Hardy \& Miller, 1997, 00:52:47 - 00:53:12)

Media 3 (animation)

Tuesday: Hey, Scrubs, what did you find? What is it you're eating?

Scrubs: I don't know but it's delicious.

Tuesday: Aw, Scrubs! (seeing a human lamp) You know I collect stuff like this.

Scrubs: My nose tells me there's more goodies up at Rocky Point.

Rosie: Look at that!

Pango: Woolly c-c-caterpillars!

Tuesday: See? I was right. This is the most incredible proof that there's another world out there!

?:(v.o.) No. Look behind you.

Tuesday: What are you talking about? Behind me? (looking at a wrecked ship) Ah! I can't believe it.

Epi: It's the thing we heard dying last night.

Kiki: What do you think it is?

Tuesday: The other world. I've got to get a closer look.

Kiki: Mak, don't! We have no idea what it is.

Pango: It's too dangerous, Mak!

Tuesday: But this is amazing! I was right! I knew it, I knew it. I knew it! This is from the other world! I have never seen anything like this! Incredible!

(Kesteloot \& Stassen, 2016, 00:18:26 - 00:19:34)

The following passages are from the main textbook. Nineteen expressions are underlined. Six are general multi-word units: 'In 1694', 'There were ', 'for three weeks', and 'in the future'. Thirteen are fusions: 'went back to $\sim$ ', came back to $\sim$ ', and 'came from Spanish America'.

Media 1 (the textbook)

$\underline{\text { In } 1694}$, Friday and I went back to my island. There were a lot of men and women there now. We 
$\underline{\text { visited them }}$ and listened to their story. The Spaniards, with Christianus and Friday's father, came back to the island after we left. They lived and worked with the English prisoners. Then more men and some women came from Spanish America. Now there were twenty children on the island too. We stayed with them for three weeks and gave them many things from our ship.

We also visited Brazil. I sent more people and animals to my island from there. Perhaps I will live on my island again in the future. But that will be a different story.

(Hopkins, \& Potter, 2000, pp. 38-39)

Applicable level: tertiary

Keywords: transmedia, transmedia storytelling, multiword units

Ryu, Do Hyung

College of General Education

Kookmin University

77 Jeongneung-ro, Seongbuk-gu, Seoul, 02707, Korea

E-mail: dohyryu@kookmin.ac.kr

Received: April 15, 2018

Revised version: May 21, 2018

Accepted: May 26, 2018 